\title{
Mr. Hulot e a desconstrução da mitologia do automóvel: uma análise de Trafic, de Jacques Tati*
}

Vander Casaqui

Doutor em Ciências da Comunicaşão pela ECA/USP.

Professor do Programa de Mestrado em Comunicação e Práticas de Consumo da ESPM-SP.

E-mail:vcasaqui@espm.br

Resumo: Este artigo desenvolve uma análise do filme Trafic, de Jacques Tati (1971), a partir do qual trata das questões do consumo, do mundo do trabalho e das intrincadas relações entre sujeitos e mercadorias no contexto contemporâneo. O quadro teórico é baseado nos estudos de Roland Barthes e Jean Baudrillard, entre outros autores que analisam os processos simbólicos que envolvem os bens, da esfera produtiva aos cenários socioculturais que revestem seu consumo pelos sujeitos.

Palavras-chave: comunicação e consumo, cinema, automóvel, trabalho.
Abstract: This paper provides a film analysis of Trafic, by Jacques Tati (1971), discussing issues of consumption, the world of work and the intricate relations among people and goods in contemporary context. The theoretical framework is based on the studies of Roland Barthes and Jean Baudrillard, among other authors that examine symbolic processes involving goods, from the productive sphere to sociocultural scenarios that cover their consumption by people.

Keywords: communication and consumption, cinema, automobile, work.

Em artigo publicado no número anterior da revista Comunicação $\mathcal{E}$ Educação, tratamos do filme Playtime, de Jacques Tati (1967) ${ }^{1}$. Na análise desta obra, discutimos a forma como o olhar do diretor desenvolve uma proposta de re-ver, de reencantar o mundo ao percebê-lo na poesia de seus arranjos e instabilidades. O humor do diretor francês, arquitetado em gags visuais, encena os choques entre o desejo de ordenação - herança moderna que em nosso contexto atual ganha complexidade e extensão por meio dos processos comunicacionais mobilizados com objetivos mercadológicos - e o consumo humano, compreendido em sentido amplo, ou seja, nas mediações que envolvem apropriações, ressignificações, recodificações dos sujeitos em relação aos estímulos e afetos que

* Este artigo continua o anterior e justifica-se pelo tema que está perseguindo: as relações comunicação, educação e consumo, caminho para a formação do sujeito participante na sociedade, com consciência, com criticidade. E o consumo é um dos pilares dessa sociedade. Ver: CASAQUI, Vander. Espacialidades, consumo e trabalho pelos olhos de Mr. Hulot: uma análise de Playtime, de Jacques Tati. Comunicação \& Educação, São Paulo: Paulinas, ano XIV, n. 3, 2009.

1. Ibid. 
lhes são estrategicamente dirigidos. No presente artigo, damos continuidade à análise do diálogo de Jacques Tati com as questões do consumo, do trabalho, dos significados das mercadorias e dos deslocamentos dos sujeitos em meio ao cenário sociocultural representado em Trafic (1971).

Em Trafic, Mr. Hulot, alterego de Tati, personagem de poucas falas, muitos gestos e uma forma peculiar de interagir com o universo a sua volta, trabalha como designer na indústria automobilística, mais especificamente na Altra, uma empresa fictícia sediada em Paris. Ele é o projetista de um novo modelo que deve ser apresentado ao público na Internationale Autoshow, feira de exposição de automóveis que será realizada em Amsterdã, Holanda; para a ocasião, desenvolve o protótipo de um automóvel para acampar, na realidade baseado no modelo Renault R4, veículo de cargas da tradicional marca francesa, cuja primeira versão foi lançada em 1961.

A narrativa cinematográfica desenvolve-se no entremeio entre produção e consumo: as primeiras imagens retratam o ambiente fabril em que peças de automóveis são preparadas, simultaneamente aos créditos iniciais do filme. O movimento das máquinas pesadas preenche a tela e os trabalhadores são como peças da grande engrenagem. A partida do caminhão que transporta o modelo para o salão do automóvel de Amsterdã demarca o início da trajetória do bem produzido para o lugar em que ele será consumido visualmente, submetido aos olhares no Centro de Convenções, pálido herdeiro do encantamento e do impacto das Exposições Universais do século XIX no imaginário de sua época. Uma estrutura de metal sem qualquer glamour, que abriga stands de marcas importantes da indústria automobilística mundial, como Volkswagen, Ford, Honda, Peugeot, Land-Rover. O cenário de um espetáculo que se materializa de maneira apática, vazia, como discutiremos adiante.

\section{OS FLUXOS DA PRODUÇÃO AO CONSUMO DOS AUTOMÓVEIS}

$\mathrm{Na}$ trajetória entre o ambiente produtivo e o espaço de consumo são apresentados os inúmeros obstáculos que separam a mercadoria de seus possíveis consumidores. A estrada empresta sua simbologia a esse fluxo dos bens, no caso, do automóvel-modelo que é transportado por um caminhão da Altra em estado precário. Os problemas se sucedem: a primeira parada é decorrente do furo de um pneu; na segunda, o combustível do

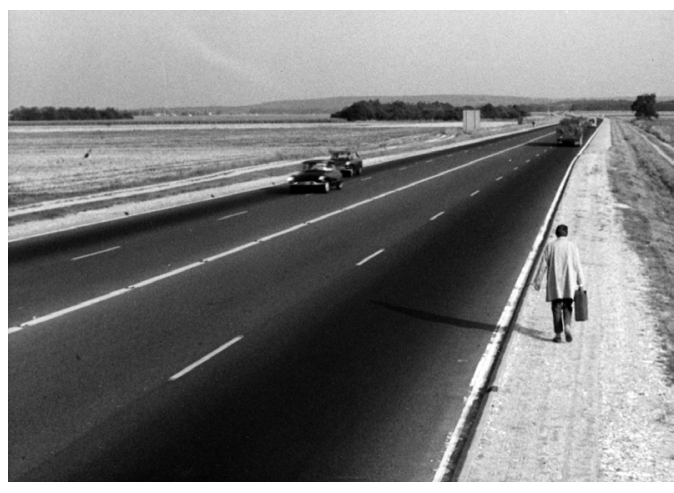

Hulot caminha na estrada, em busca de um posto de gasolina (fig. 1) 
Mr. Hulot e a desconstrução da mitologia do automóvel • Vander Casaqui

de um posto de gasolina, com um galão vazio, como se vê na imagem (fig. 1), uma das muitas cenas emblemáticas e repletas de simbologias do filme.

A imagem do caminhão quebrado, que transporta o possível objeto de desejo no espectro da sociedade de consumo - a mercadoria nova, ainda em protótipo -, sugere um corredor isotópico, reiterativo da ideia de um sistema

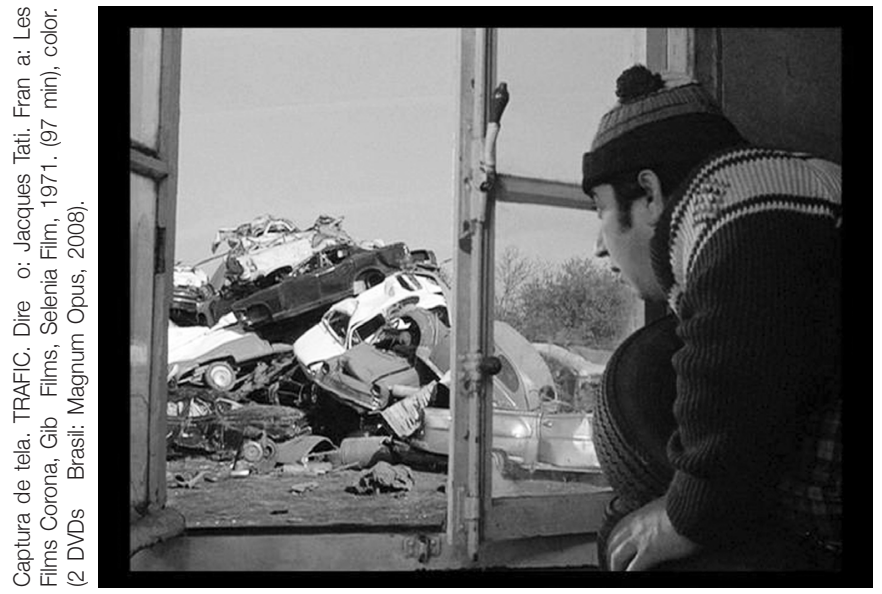

A imagem de carros destru dos presen a constante no filme Trafic (fig. 2).

que maquia seus problemas e, ao revestir o produto final de camada estética, cobre de maneira efêmera aquilo que seria a deficiência estrutural do modelo. De maneira insistente, saltam aos olhos as imagens que promovem o desencanto gradativo do automóvel e do ser humano que nele se instala. São recorrentes as colisões, as quebras, os carros destruídos, como signos de uma visão crítica do consumo relativo aos veículos (fig. 2).

No trajeto, ao passar pelo controle de fronteira com a Bélgica sem parar, o caminhão da Altra é levado para a garagem da polícia rodoviária, onde os veículos permanecem até ser liberados. Enquanto a documentação da Altra é analisada, os policiais começam, um a um, a se interessar pelo modelo transportado: o veículo para camping, nesse momento, passa a ser o centro das atenções do lugar. De maneira surpreendente, aquele local transforma-se em uma espécie de exposição, em que o protótipo é apreciado, experimentado, enfim, promove o encantamento que, em tese, teria seu lugar específico no centro de convenções que abriga a feira de autos. O motorista do caminhão, a assessora de relações públicas e Hulot, o designer do modelo, desdobram-se para demonstrar os vários recursos pensados por seu criador para suprir as necessidades da situação de acampar (fig. 3). Ao passo que os olhares dos policiais se encantam com os elementos do veículo, fundados na busca por funcionalidade, por atender às carências humanas por meio de engenhocas, de mecanismos diversos, o espectador compartilha o olhar irônico do diretor, a evidenciar a irracionalidade,

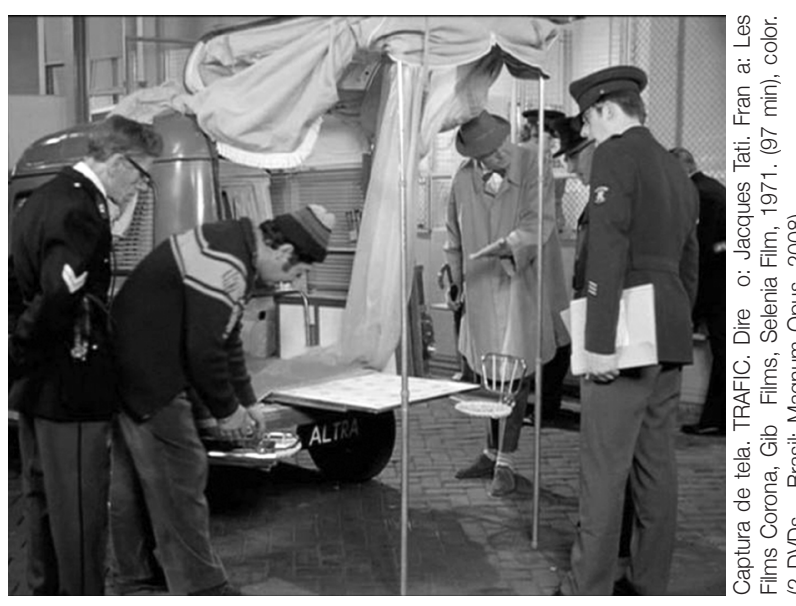

Hulot demonstra as funcionalidades de sua cria o: uma mesinha e duas cadeiras acopladas parte traseira do modelo camping da Altra (fig. 3). 
a ausência de sentido por detrás dos gadgets que preenchem a vida cotidiana moderna. De acordo com Barthes,

[...] acreditamos estar num mundo prático de usos, de funções, de domesticação total do objeto, e na realidade estamos também, pelos objetos, num mundo do sentido, das razões, dos álibis: a função faz nascer o signo, mas esse signo é transformado no espetáculo de uma função².

É nesse processo, o qual envolve a naturalização dos signos ou, no caso do filme, a construção do sentido para o uso de objetos que anseiam ser incorporados em nosso cotidiano, que está a ideologia da sociedade de consumo. Já para Baudrillard ${ }^{3}$, a automatização e a multifuncionalização, em última instância, revelam o papel do homem como objeto em meio a um sistema de objetos, que lhe instauram como tal a partir de comandos, de modos de usar, de funções que devem ser exercidas para que possam se manter ativos.

Baudrillard, em sua obra $O$ sistema dos objetos, fala sobre o imaginário em torno do automóvel, comparando-o à casa:

[...] o carro faz mais do que se opor à casa em uma cotidianidade desdobrada: é também um domicílio, mas excepcional, uma esfera fechada de intimidade, mas desligada dos embaraços habituais da intimidade, dotada de uma intensa liberdade formal, de uma funcionalidade vertiginosa. A intimidade do lar é a da involução na relação doméstica e no hábito, já a do automóvel é a de um metabolismo acelerado no tempo e no espaço, ao mesmo tempo o lugar sempre possível do acidente [...]. O carro constitui assim o centro de uma subjetividade nova cuja circunferência não se acha em parte alguma enquanto a subjetividade do mundo doméstico é circunscrita. ${ }^{4}$

Diante do pensamento de Baudrillard, é interessante perceber o veículo modelo camping, simultaneamente englobando os dois sentidos de domicílio: ao mesmo tempo que é uma nova forma de subjetividade, uma ambiência para o sujeito que estabelece novas relações de espaço e tempo em relação à casa, pode se transformar na casa em sentido mais estreito, com aconchegos proporcionados pela funcionalidade de sua engenharia. $\mathrm{O}$ conforto, traduzido pelas concepções tecnológicas aplicadas aos bens de consumo, naquele momento histórico tinha um paradigma: a chamada casa do futuro, em que tudo poderia ser automatizado. Nesse sentido, Trafic retoma um tema narrativizado em Meu tio (1956), o filme em que Tati lança seu olhar à arquitetura moderna e ao fetiche tecnológico, no qual o homem fica refém do funcionamento quase autônomo, ou por vezes indecifrável, dos objetos que compõem a casa moderna, plena de recursos eletrônicos,

2. BARTHES, Roland. Semântica do objeto. In: A aventura semiológica. São Paulo: Martins Fontes, 2001. p. 218

3. BAUDRILLARD, Jean. O sistema dos objetos. 2. ed. São Paulo: Perspectiva, 1989.

4. Ibid., p. $75-76$ por onde transitam os personagens. Em Trafic, ao contrário de Meu tio, todos os engenhosos recursos que transformam o veículo em pseudolar funcionam: isqueiro e porta-sabão, minicozinha, cama dupla, TV, até mesmo um barbeador no volante - no lugar da buzina (!!) -, e uma grelha para assar carnes, embutida na tela de proteção do carburador (!!!); tudo compõe um irônico sentido de casa moderna, a partir de engenhosas adaptações e transmutações do espaço e dos mecanismos do veículo. No caso, a falibilidade está no próprio automóvel - uma vez que o protótipo é dependente do transporte por caminhão para chegar a seu destino. 


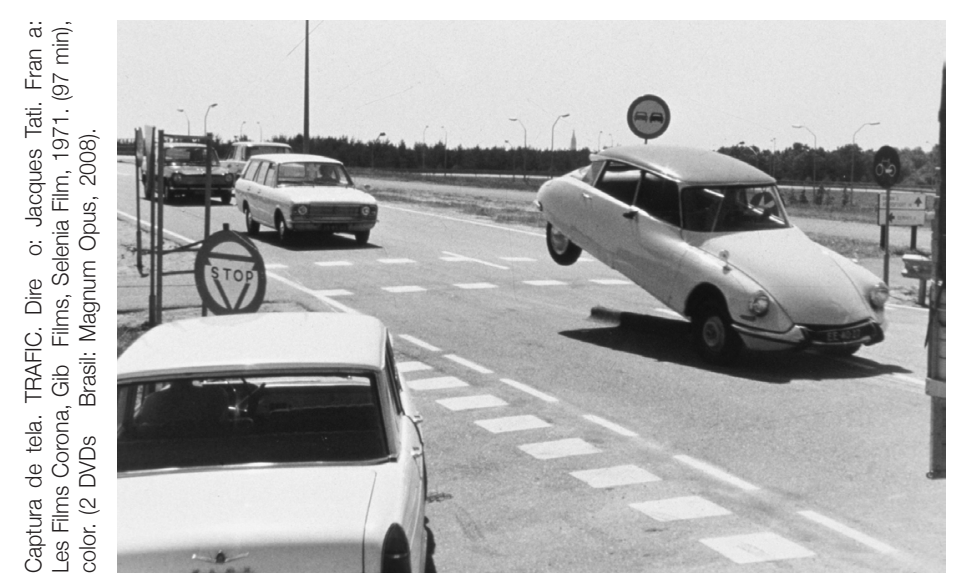

Imagem do grande engavetamento em que a poesia de Tati emoldura a violência dos acidentes (fig. 4).
O automóvel, interrompido em seus fluxos, em seu deslocamento, equipara-se ao tempo da casa. Quando o transporte do modelo para a exposição supera os problemas mecânicos, depara-se com os congestionamentos ou sofre colisões. Dessa maneira, o personagem Hulot faz parte, ainda que de forma um tanto quanto distanciada, da falência do projeto moderno: a máquina que conduz o homem, como metáfora do progresso, é impedida de prosseguir. Talvez a cena mais memorável do filme seja o momento em que, no cruzamento entre vias por onde passa o caminhão da Altra, ocorre um grande engavetamento. Mais uma vez, como em Playtime, objeto de nossa análise anterior ${ }^{5}$, os automóveis compõem um circuito de movimentos coordenados: em Playtime os carros, em uma rotatória, lembram, de forma poética, um carrossel de parque de diversões. Tati, em Trafic, monta reações em cadeia a partir das colisões dos veículos, promovendo movimentos que expressam certa poesia na composição do caos, no acidente em grandes proporções na autopista (fig. 4). O olhar não é mais o da criança, que encontra a magia, a ingenuidade, a graça na forma como os sujeitos ficam à mercê das máquinas, no caso, do congestionamento. Aqui, é o adulto que ri do absurdo, que mostra a violência e a atenua com o humor, mas não a esvazia. Tati lança sua crítica à forma como o ser humano se transforma quando senta ao volante, principalmente na loucura das grandes cidades e da enorme quantidade de veículos que se encontram a cada cruzamento, a cada esquina: o choque entre veículos é, em última instância, o desencontro entre seres da mesma espécie, de sujeitos que se confrontam, que abandonam os princípios da civilidade, da convivência harmônica pelo uso da máquina (fig. 5). Nada mais atual, principalmente para quem vivencia cotidianamente a situação caótica do trânsito das grandes cidades, que somente se agrava com o passar dos anos.

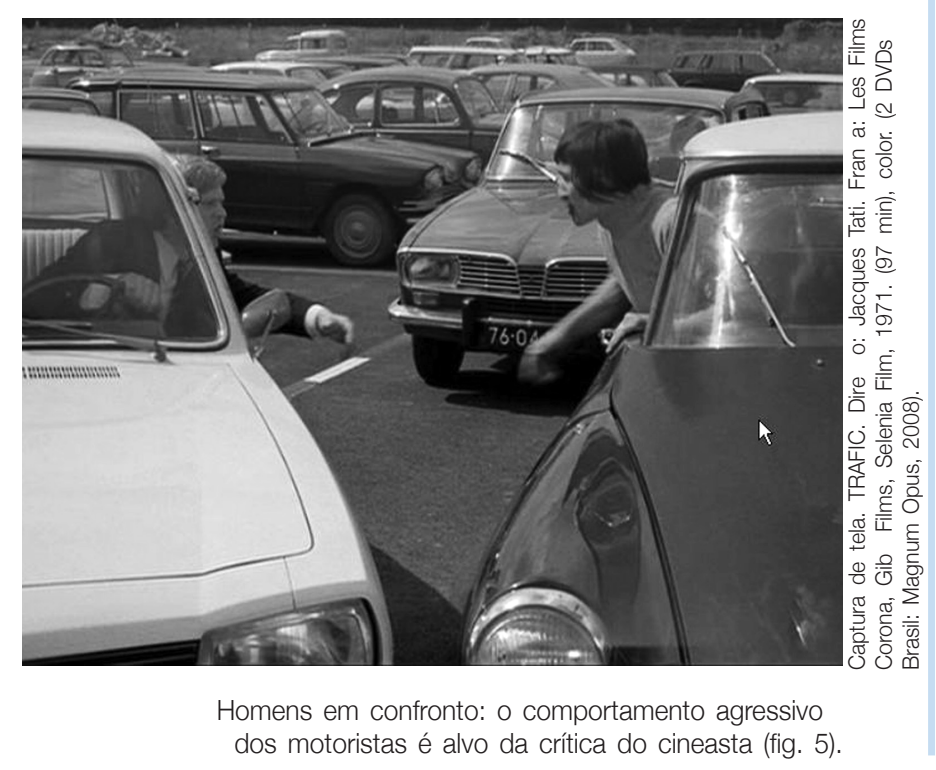

5. CASAQUI, Vander. Espacialidades, consumo..., cit. 
comunicação \& educação • Ano XV • Número 1 • jan/abr 2010

\section{DO OLHAR DESENCANTADO E DO ENCANTAMENTO DO OLHAR}

Apesar de acentuar seu olhar crítico sobre a condição humana em relação a filmes anteriores, a partir da situação do trânsito, Tati mantém seu estilo peculiar, na composição de cenas inusitadas, decorrentes do deslocamento de elementos cotidianos, gerando assim interpretações improváveis de situações a princípios comuns. Após o grande acidente, homens e mulheres, atordoados, saem de seus automóveis em movimentos ora lentos, ora agitados, como se to-

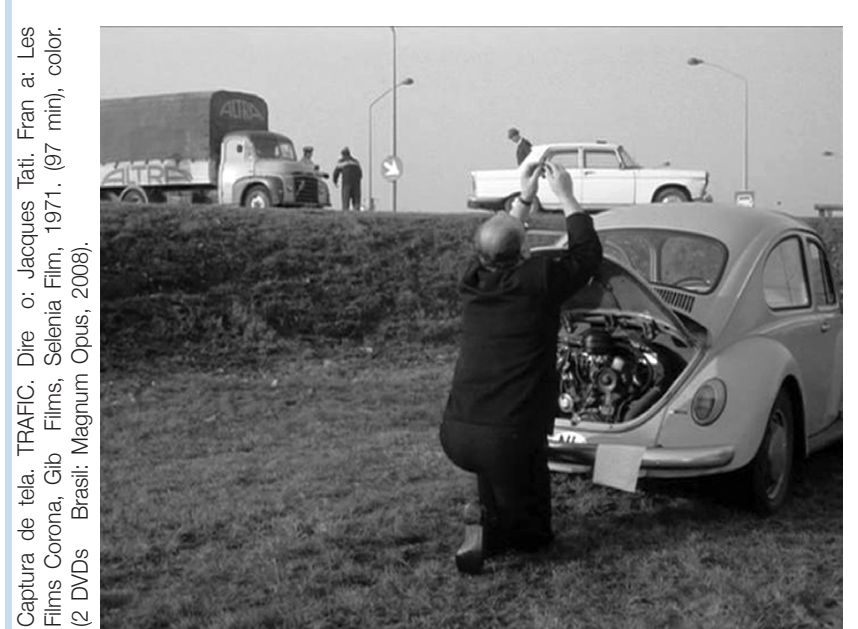

Uma das cenas inusitadas, marca registrada do cinema de Tati o padre observa uma pe a de seu autom vel, em gesto que lembra uma missa cristã (fig. 6). dos tivessem perdido o rumo. Diante desse cenário, Tati extrai imagens que fazem rir pelo estranhamento, como no momento em que um padre, motorista de um Volkswagen sedã, conhecido popularmente no Brasil como fusca, abre a tampa do motor em gestos que mais lembram a celebração de uma missa cristã - levanta a peça do motor como se fosse uma hóstia, gesticula em frente ao carro como se estivesse no altar (fig. 6).

A narrativa de Trafic estabelece alguns contrapontos, a partir dos quais se organizam os sentidos do consumo e das ações dos sujeitos. Por um lado, faz crítica feroz à automatização das pessoas, em meio ao uso das máquinas, no cenário urbano; por outro, desenvolve uma visão bem-humorada para os tipos que estão no caminho que vai de Paris a Amsterdã, onde acontece a exposição de automóveis - gente do campo, com características ímpares, com uma dimensão humana que escapa do ritmo e da automatização das multidões da cidade. É nesse lugar que Hulot parece identificar-se, ser ele mesmo, compor harmonicamente o cenário, e não se manter à parte, como um pária em meio ao contexto corporativo, ou um outsider das grandes metrópoles, como é Paris, onde trabalha como designer. É ilustrativo dessa situação os momentos divertidos em que o grupo da Altra, que espera o conserto do automóvel camping, avariado no gigantesco acidente da autopista, faz um piquenique com o mecânico, à beira de um canal, com a natureza esplendorosa ao fundo (fig. 7). O contraste acentua-se quando vemos Hulot, em meio a um congestionamento, tentando dar ordem ao caos, ao voltar à estrada para tentar chegar a Amsterdã a fim de expor sua criação (fig. 8).

A câmera reflexiva de Tati abre espaço para mostrar personagens anônimos em meio ao trânsito, e de que forma essa situação de espera e, como não dizer, 
Mr. Hulot e a desconstrução da mitologia do automóvel • Vander Casaqui

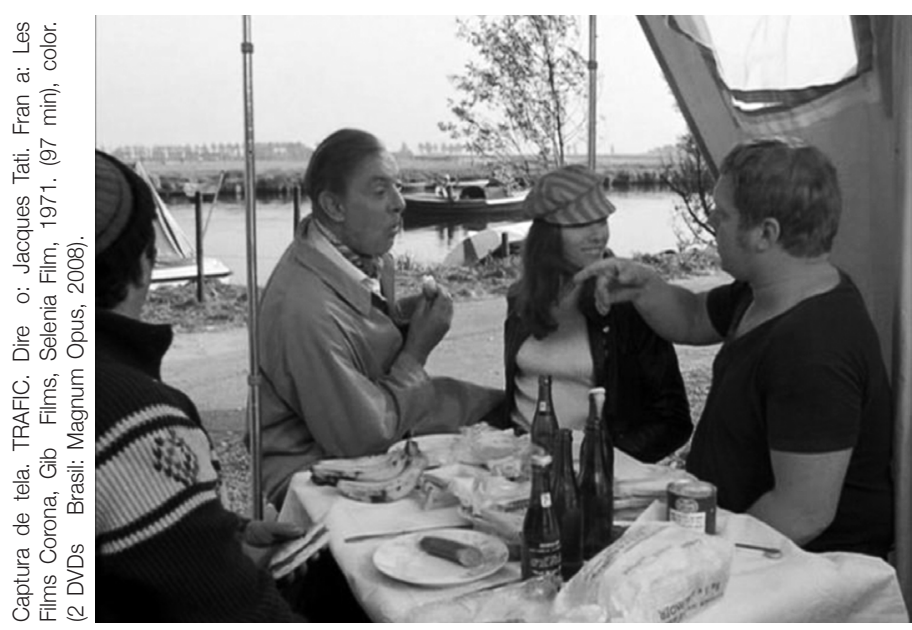

Hulot próximo à assessora de relações p blicas, ao lado do motorista do caminh o da Altra e conversando com o mec nico: um momento de tranquilidade, de harmonia, em contraponto ao caos do tr nsito, que vemos na cena abaixo (fig. 7).

de certa sensação de intimidade, mesmo que vigiada através dos vidros transparentes dos automóveis, pode gerar comportamentos, no mínimo, curiosos. São pessoas bocejando, paralisadas, movimentando-se de forma engraçada, e até aproveitando o tempo para fazer a higiene das narinas, em uma sequência de imagens tão bizarra quanto hilária (fig. 9).

Os personagens que

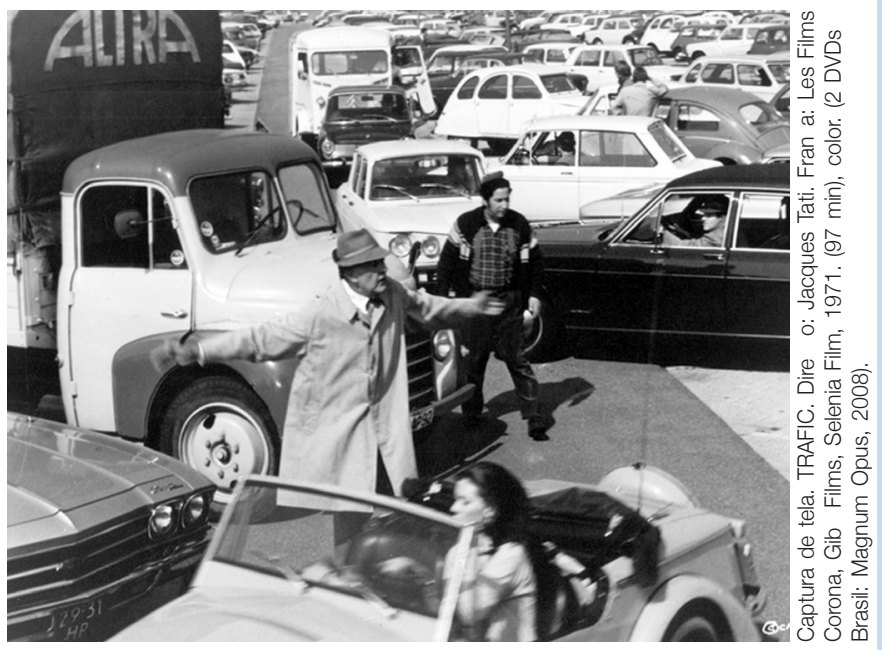

Figura 8 aparecem e desaparecem da narrativa do filme, circulando pela feira de automóveis, formam um ca-

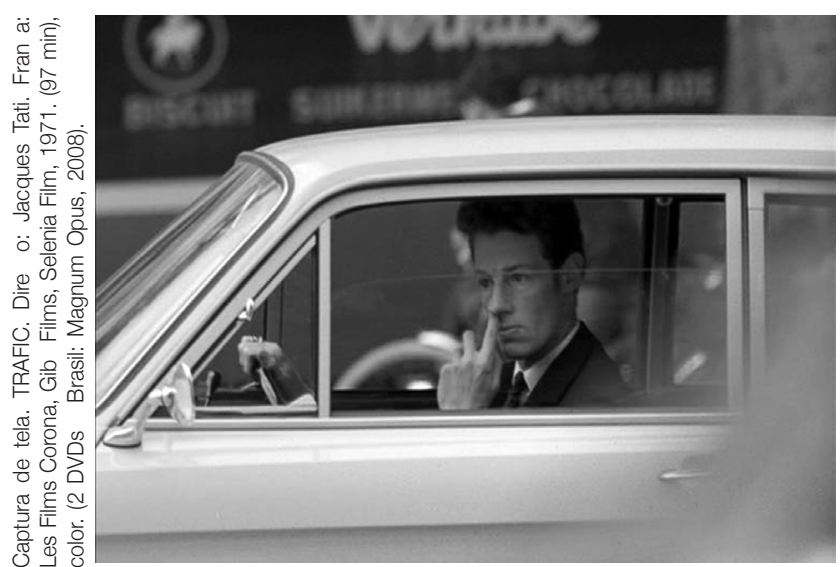

Para Tati, a gra a est nos detalhes do cotidiano na imagem acima, o humor est na observa o da maneira como os motoristas aproveitam o tempo quando est o parados no trânsito (fig. 9). pítulo à parte: no espaço do centro de convenções, os seus visitantes são observados por uma câmera que busca o humor nos possíveis arranjos de cena entre homens e máquinas. Em determinado momento, os gestos de levantar e bater as tampas de capôs e porta-malas dos carros em exposição compõem uma improvável e breve sinfonia de ruídos. Em outra situação, homens que se debruçam para ver os detalhes de um motor, vistos pela câmera no alto, formam a 


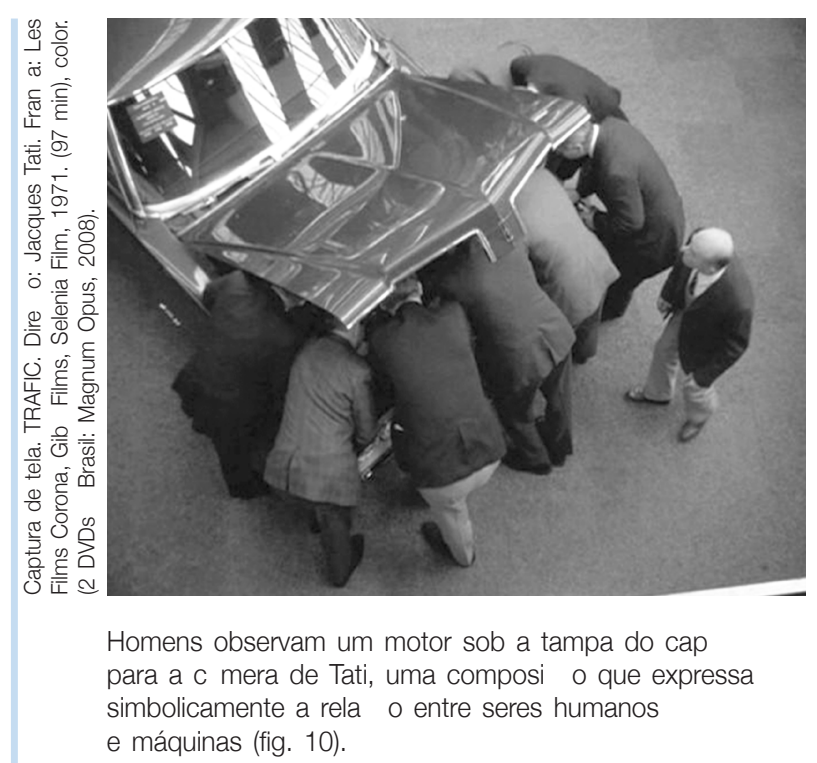

objetos, agora na esfera do consumo, como sugere Tati em seu Trafic.

Giucci, em seu profundo estudo sobre $A$ vida cultural do automóvel ${ }^{6}$, percorre seus significados através do século XX, desde os primórdios, como anúncio de uma nova era, entusiasticamente louvado pelo Manifesto Futurista (escrito por Filippo Tommaso Marinetti e publicado no jornal francês Le Figaro, em fevereiro de 1909), passando pela contracultura norte-americana de meados do século e pela sua forte identificação com o american way of life, chegando a nossos dias em meio à cultura do espetáculo, revestido por narrativas, simbologias, mitologias. É nesse cenário que Jacques Tati lança suas observações mais instigantes sobre o culto ao automóvel. Na exposição de Amsterdã, lugar construído para a mitificação dos modelos, apresentados em meio a cenários, jogos de luzes, bases móveis, percebemos os olhares apáticos dos visitantes, como se o consumo simbólico desses bens padecesse da saturação de imagens de nosso tempo, decorrente do imbricamento da cultura midiática com o cotidiano. Os carros mostrados são nada mais que protótipos, carros cortados ao meio, sem motores, sem funções para além de cooptar o olhar e ser consumido simbolicamente (fig. 11). São como fantasmagorias, máscaras que buscam concentrar em sua superfície significados que se desvinculam de suas materialidades.

Ao mesmo tempo que o culto da mercadoria auto-

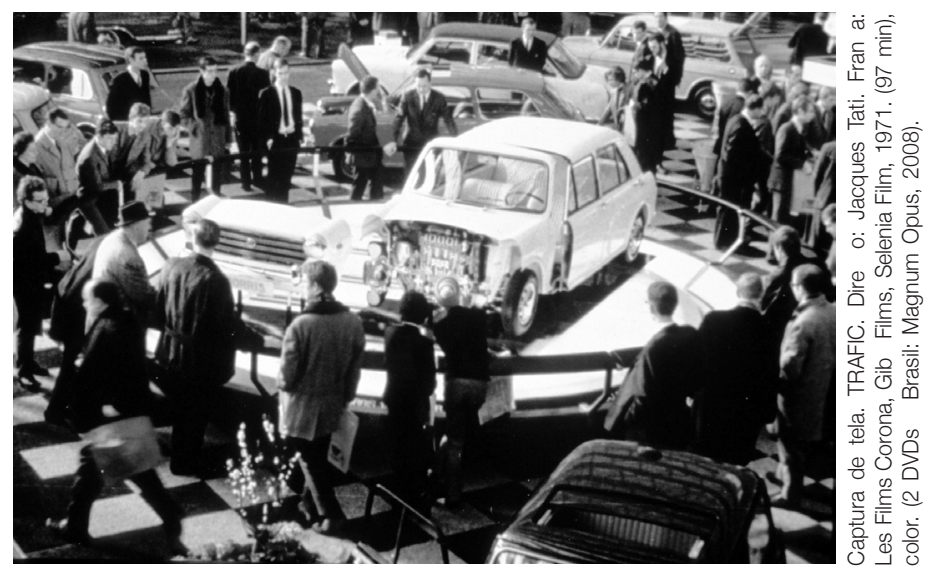

Carro em exposi o na feira do autom vel de Amsterd a cultura do espet culo transforma os autom veis em fantasmagorias, em máscaras que produzem novos significados para seduzir o olhar dos consumidores (fig 11). 
Mr. Hulot e a desconstrução da mitologia do automóvel • Vander Casaqui

móvel acontece, Hulot permanece distante: a sua criação, o modelo camping da Altra, chega ao centro de convenções quando a feira de automóveis já se encerrara. Durante todo o caminho, desde a saída de Paris, acompanhamos pelas telas de aparelhos de TV o foguete norte-americano Apollo 11, a primeira missão a pisar na lua, em 1969. As imagens que prenderam a atenção de milhões de telespectadores em todo o

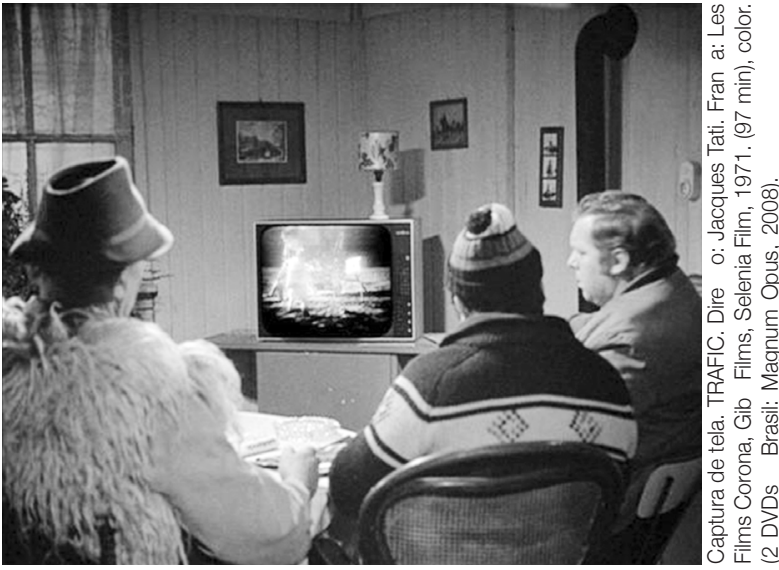

Hulot, o motorista do caminh o e o mec nico observam a missão Apollo 11 pisando na superfície da lua (fig. 12). mundo parecem dizer pouco, ou nada a Hulot, que permanece indiferente a elas, até ser chamado pelo mecânico que conserta o protótipo da Altra para vê-las em sua televisão (fig. 12).

O pano de fundo midiático eleito por Jacques Tati para seu filme é emblemático: diante dos conflitos do homem com as máquinas que criou, especificamente o automóvel, parece algo surreal, distante deste mundo em que vivemos, a ideia de que este mesmo homem seja capaz de chegar à lua. Mídia, exposições, mundo corporativo: coisas que compõem a trajetória de Mr. Hulot, mas que não lhe afetam a ponto de perder a identidade, o olhar distanciado, de quem vem de outro mundo e apenas observa à distância. Quando tenta se adaptar, percebe o quanto essa distância é intransponível. Ao final do filme, ele é despedido pelo diretor da Altra, enfurecido pela impossibilidade de expor o lançamento de sua companhia na feira de automóveis. Hulot não se abala; ao sair, passa diante do modelo que concebeu como designer, estacionado à frente do centro de convenções, fazendo sucesso com uma multidão de pessoas, que o observam e disputam os seus folhetos de divulgação. Missão cumprida, apesar dos obstáculos.

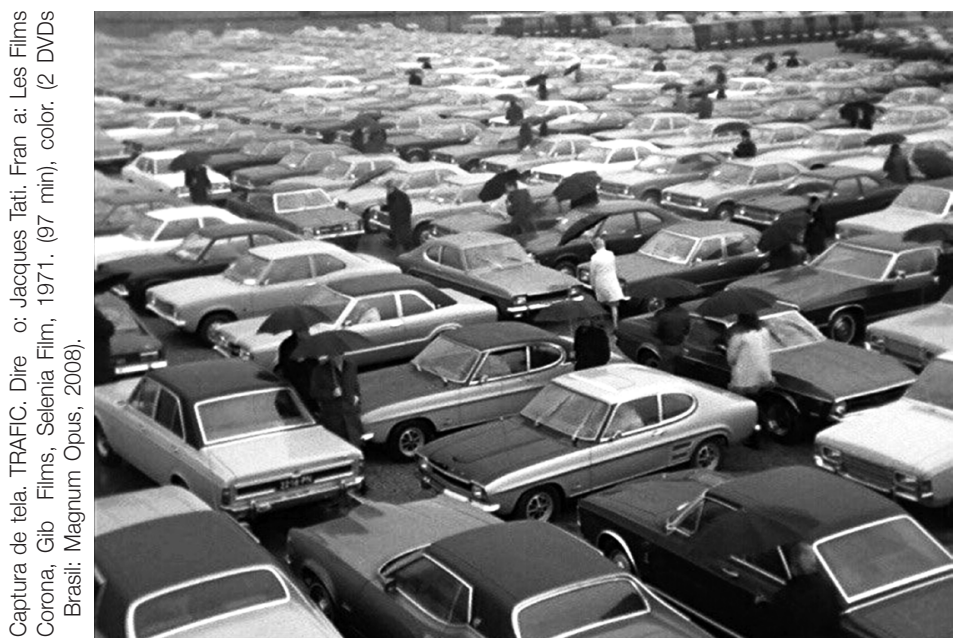

Hulot segue a pé, cobrindo-se da chuva, atravessando o mar de automóveis, na cena final de Trafic (fig. 13).

A chuva chega. Com ela, Tati sinaliza esperar tempos obscuros por vir. Seu alterego, precavido, abre o guarda-chuva e caminha em meio a um mar de automóveis parados (fig. 13). Diante da incerteza dos novos tempos, Hulot se protege com sua história, com sua identidade, com seu jeito peculiar de ser. Mais um recado do mestre francês que vale pela eternidade. 
comunicação \& educação • Ano XV • Número 1 • jan/abr 2010

\section{REFERÊNCIAS BIBLIOGRÁFICAS}

BARTHES, Roland. Semântica do objeto. In: A aventura semiológica. São Paulo: Martins Fontes, 2001.

BAUDRILLARD, Jean. O sistema dos objetos. 2. ed. São Paulo: Perspectiva, 1989.

CASAQUI, Vander. Espacialidades, consumo e trabalho pelos olhos de Mr. Hulot: uma análise de Playtime, de Jacques Tati. Comunicação \& Educação, São Paulo: Paulinas, ano XIV, n. 3, 2009.

GIUCCI, Guillermo. A vida cultural do automóvel: percursos da modernidade cinética. Rio de Janeiro: Civilização Brasileira, 2004.

\section{Filmografia}

TRAFIC. Direção: Jacques Tati. Intérpretes: Jacques Tati e outros. Roteiro: Jacques Tati e Jacques Lagrange. França: Les Films Corona, Gibé Films, Selenia Film, 1971. 97 min, color. (2 DVDS - Brasil: Magnum Opus, 2008). 